University of Nebraska - Lincoln

DigitalCommons@University of Nebraska - Lincoln

Agronomy \& Horticulture -- Faculty Publications

Agronomy and Horticulture Department

1969

Gaseous Exchange in Crop Stands

Edgar Lemon

Agricultural Research Service, USDA

Follow this and additional works at: https://digitalcommons.unl.edu/agronomyfacpub

Part of the Plant Sciences Commons

Lemon, Edgar, "Gaseous Exchange in Crop Stands" (1969). Agronomy \& Horticulture -- Faculty Publications. 184.

https://digitalcommons.unl.edu/agronomyfacpub/184

This Article is brought to you for free and open access by the Agronomy and Horticulture Department at DigitalCommons@University of Nebraska - Lincoln. It has been accepted for inclusion in Agronomy \& Horticulture -Faculty Publications by an authorized administrator of DigitalCommons@University of Nebraska - Lincoln. 
Published in Physiological Aspects of Crop Yield: Proceedings of a symposium sponsored by the University of Nebraska, the American Society of Agronomy, and the Crop Science Society of America, and held at the University of Nebraska, Lincoln, Nebr., January 20-24, 1969. Edited by Jerry D. Eastin, F. A. Haskins, C. Y. Sullivan, C. H. M. Van Bavel, and Richard C. Dinauer (Madison, Wisconsin: American Society of Agronomy \& Crop Science Society of America, 1969). Copyright (C) 1969 American Society of Agronomy \& Crop Science Society of America. Used by permission. 


\title{
6
}

\section{Gaseous Exchange in Crop Stands 1}

\author{
EDGAR LEMON \\ Agricultural Research Service, USDA \\ Ithaca, New York
}

\section{PROBLEMS OF MEASUREMENT AND UNDERSTANDING}

Man through the ages has evolved a strategy, albeit empirical, of manipulating the environment and the plant to his advantage. Practices such as fertilizing the soil, irrigation, weed control, and plant breeding and selection are common. Nonetheless, concentrated and coordinated efforts to understand the mechanisms controlling the whole soilplant-atmosphere continuum is a new approach to finding new ways to favorably manipulate the whole system as well as predict response.

Conceptually and experimentally it has proven advantageous to view the total system in terms of energy, momentum, and mass exchange. This makes sense because in the first instance the foundations of crop production and water use are based upon two solar energy conversion processes-photosynthesis and evaporation. In the second instance, the momentum exchange of the wind creates the necessary turbulent ventilation to diffuse heat, water vapor, carbon dioxide, and oxygen. Of course, all of these exchange processes are driven by a common energy source-the sun.

My subject in this paper focuses on the ventilation of crop stands. We shall be mainly concerned with the turbulent diffusion of the physical properties of the air. The movement of air in crop stands has relevance to photosynthesis and respiration through the exchange of carbon dioxide and oxygen with the atmosphere. It has relevance also to transpiration through the exchange of water vapor and heat. Over the past 5 years we have taken advantage of the physics of turbulent diffusion to measure the rates of gaseous exchange layer-by-layer within the cano-

${ }^{1}$ Contribution from the Northeast Branch of the Soil and Water Conservation Research Division, ARS, USDA, in cooperation with the New York State Agricultural Experiment Station at Cornell University, Ithaca, N.Y., and the Atmospheric Sciences Research Division, US Army Electronics Command, Fort Huachuca, Áriz. Cornell University Department of Agronomy Series Paper no. 841. 
pies of some crops (Begg, et al., 1964; Brown and Covey, 1966; Denmead, 1964, 1966; Inoue, et al., 1968; Lemon, 1967; Lemon and Wright, 1969; Wright and Lemon, 1966; Uchijima, 1962a, 1962b). Our primary purpose has been to relate environmental factors to plant response. From such studies we have hopes of improving the architecture of crop stands not only for light capture but for optimum ventilation as well. The latter is needed for optimizing plant temperature, and supply of $\mathrm{CO}_{z}$ and minimizing water vapor loss. Ultimately the ideal crop structure will be a compromise for all of these attributes and will be specific for the crop product and the climate under which it is grown.

How well do we understand the physics of gaseous exchange and what are the chief problems of measuring it in the field? It seems appropriate after 5 years of progress to explore the answers to these questions at this symposium. I will focus only on the major weak points still needing attention. As a beginning I will briefly take up the methods of measurement. Since the methods are based upon the natural physical processes at work in the field much can be gained by understanding their principles. Later we will speculate about some relevant facets of the aerodynamic processes important to crop production.

\section{A. Brief Review of Energy and Momentum Balance Methods of Measuring Gaseous Exchange in Crop Stands}

To date most of our studies have dealt with large uniform fields of agricultural crops where we measure the energy and gaseous exchange in a vertical direction. This exchange is usually expressed in units of flux intensity, i.e., calories or grams per square centimeter of land surface per minute. During this talk I will concentrate on the exchange of $\mathrm{CO}_{2}$ and momentum but the principles apply equally as well to exchange of the other physical properties of the air such as heat and water vapor.

Figure 6-1 is intended to picture the energy balance method or model to determine $\mathrm{CO}_{2}$ exchange. In the upper left-hand corner the little box represents a layer or slab of a crop which is photosynthesizing, taking out of the air the amount of $\mathrm{CO}_{3}=\mathrm{QP}$. The flux intensity at the top diffusing downward is $\mathrm{P}+\Delta \mathrm{P}$ and the flux intensity at the bottom diffusing downwards is $P$. Thus the difference between $P+\Delta P$ and $P=$ QP. Expressed in another way, the sink strength, QP is equal to the derivative of the flux intensity on height, $\mathrm{dP} / \mathrm{dz}$. The name of the game is determining the flux intensity, $\mathrm{P}$, at several levels of $\mathrm{z}$ in a crop canopy. In the lower left-hand corner of the figure you will find the treatment for one level $\mathrm{z}$. Here the $\mathrm{CO}_{2}$ flux intensity $\mathrm{P}$ is equal to the diffusivity coefficient of $\mathrm{CO}_{2}$ in the air, $\mathrm{K}_{\mathrm{c}}$, and the $\mathrm{CO}_{2}$ concentration gradient on height, $\mathrm{dc} / \mathrm{dz}$. Getting $\mathrm{dc} / \mathrm{dz}$ is not too difficult; it is the slope of the $\mathrm{CO}_{2}$ profile at $\mathrm{z}$ pictured in the insert. Today we are fairly confident in obtaining good $\mathrm{CO}_{z}$ profiles. The major problem comes in evaluating $\mathrm{K}_{\boldsymbol{C}}$ in order to solve the equation for $\mathrm{P}$. Here one has to assume that in a turbulent wind regime, such as commonly occurs outof-doors, the diffusivity coefficients for other physical properties of the air are the same as they are for $\mathrm{CO}_{3}$. We have not learned how to de- 

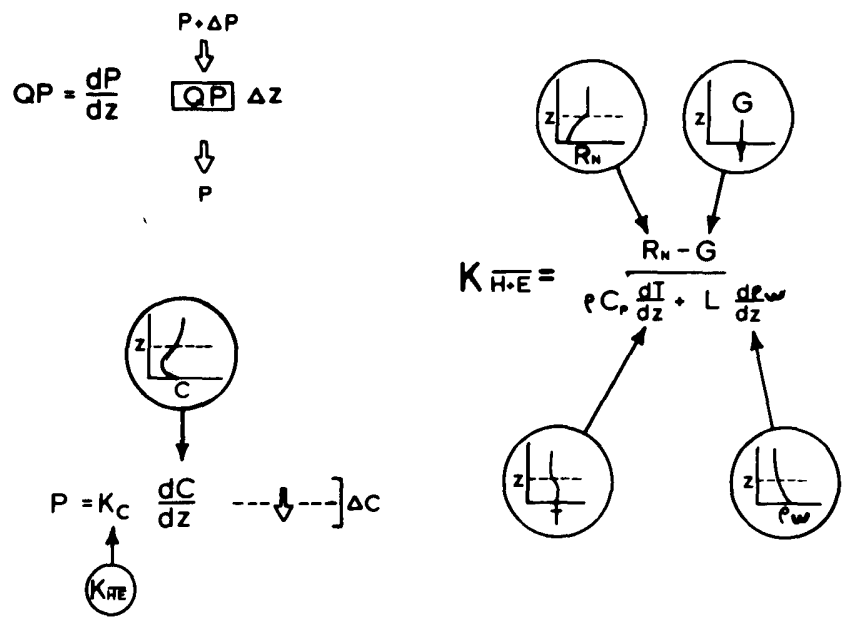

\section{ENERGY BALANCE MODEL}

Fig. 6-1-The energy balance model used to measure $\mathrm{CO}_{2}$ exchange in plant communities (see text and Lemon, 1967).

termine $\mathrm{K}_{\mathrm{c}}$ independently of $\mathrm{P}$ or $\mathrm{dc} / \mathrm{dz}$. By assuming the diffusivities are equal, however, one can turn to either the momentum or energy budget for a fair approximation of $\mathrm{K}_{\mathrm{c}}$. The right-hand side of Fig. 6-1 gives the energy balance method of determining a diffusivity coefficient which is the mean for heat and water vapor. The inserts depict the field measurements needed. These measurements have to be taken simultaneously with the $\mathrm{CO}_{3}$ profile. These are: profiles of net radiation, $\mathrm{RN}$; temperature, $\mathrm{T}$; and water vapor, $\rho \mathrm{w}$, as well as soil heat flux, $\mathrm{G}$. The slopes of these profiles at $\mathrm{z}$ give the derivatives desired. The other symbols in the equation are known constants. Once $\mathrm{K}$

\section{$\overline{\mathrm{H}} \& \mathrm{E}$} is evaluated

it is substituted for $\mathrm{K}_{\mathrm{c}}$, then $\mathrm{CO}_{2}$ flux intensity, $\mathrm{P}$, is calculated.

Figure 6-2 gives the momentum balance method of approximating $\mathrm{K}_{\mathrm{c}}$. Here the diffusivity coefficient for momentum, $\mathrm{K}_{\mathrm{m}}$, is substituted in the $\mathrm{CO}_{z}$ flux equation. Now turn directly to the right side of the figure. In the upper right-hand corner is an insert containing a wind speed profile. It is obvious that the wind speed, $u$, decreases with decreasing height, $z$. Since air has mass, a decrease in velocity is indicative of friction or "drag" on the crop surfaces. The loss of momentum is "transferred" to the crop. This downward flux intensity of momentum, $\tau$, "diffuses" in a manner similar to the other physical properties of the air, thus the process can be defined by an equation similar to the diffusion equation for $\mathrm{CO}_{2}$. The equation on the upper right side is the diffusion equation for momentum rearranged so that the diffusivity coefficient $\mathrm{K}_{\mathrm{m}}$ is equal to the momentum flux intensity, $\tau$, divided by the wind speed gradient, $\mathrm{du} / \mathrm{dz}$, and the air density, $\rho$. The wind speed gradient, 


\section{MOMENTUM BALANCE MODEL}

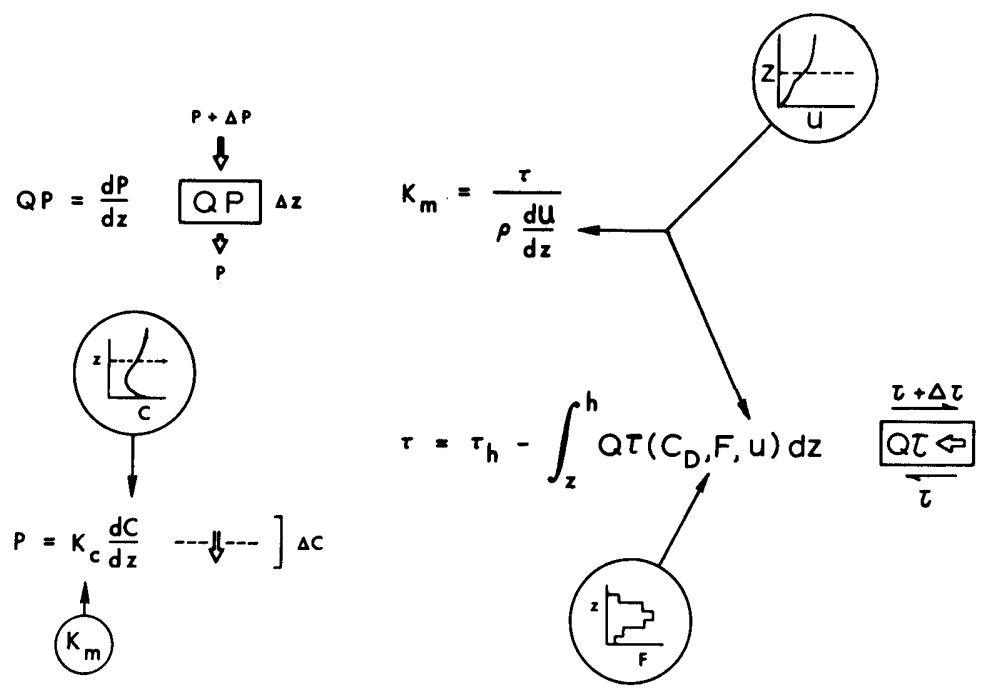

Fig. 6-2-The momentum balance model used to measure $\mathrm{CO}_{2}$ exchange in plant communities (see text and Lemon, 1967).

$\mathrm{du} / \mathrm{dz}$, is the slope of the wind profile at $\mathrm{z}$. Good wind speed profiles can be obtained with care.

The evaluation of the momentum flux intensity, $\tau$, at a given level in the crop presents difficulties. In effect one determines the "drag" of the whole crop by evaluating the total momentum flux intensity at the top of the crop, $\tau_{\mathrm{h}}$, then partitions the momentum exchange with depth below the top of the stand as a function of foliage surface density $F$ and and wind speed, $u$. This scheme is found in the lower right of Fig. 6-2. First, look at the little box representing a slab or layer of crop. The momentum flux intensity at the top is $\tau+\Delta \tau$ and at the bottom $\tau$. The difference between the top and bottom gives the sink for momentum in the layer, $Q \tau$. This force per unit volume of crop stand is related to the foliage area density, the wind speed and a "drag coefficient," ( $\left.\mathrm{C}_{\mathrm{D}}\right)$ characteristic of the surfaces in the crop. Integrating this drag force, $\mathrm{Q} \tau$, from a height $\mathrm{z}$ to the top of the stand, $\mathrm{h}$, is given by the equation. The inserts indicate the field measurements needed, the distribution of wind speed, $u$, and foliage area density, $F$. These measurements are not too difficult. The total shear at the top of the stand, $\tau_{h}$, is determined from classical analysis of the $\log$ wind profile above the crop. As in the energy balance, wind speed and $\mathrm{CO}_{3}$ profiles have to be made simultaneously. Once knowing $\tau_{h}$ and the integral of $Q \tau$ from $z$ to $h$, one can solve for $\tau$, then for $K_{m}$, and finally for $P$ by substituting $K_{m}$ for $\mathrm{K}_{\mathrm{c}}$.

However, two critical assumptions have to be made about $\mathrm{CD}_{\mathrm{D}}$, the "drag coefficient" characteristic of the crop surfaces: (i) that it is a 
constant for all surfaces in the crop, and (ii) that it is independent of wind speed. Neither assumption is correct. This will be the subject of further comments later.

\section{B. Some Weak Points in the Methods}

\section{The Heat Budget}

Perhaps the most serious problem in using the energy balance to study gaseous exchange within the stand is the satisfactory measurement of net radiation. This is a sampling problem and has much in common to properly sampling for light distribution within the stand. Spatial variation is extremely great and special pains have to be taken to obtain an adequate sample. This subject has been adequately aired in Dr. J. L. Monteith's earlier discussion (Chapter 5, this book) and I will not dwell on it further here.

\section{The Momentum Budget}

I would like now to spend considerable time discussing the "aerodynamics" of crops because of its importance not only in the use of the momentum balance for measuring exchange but its importance to crop climate, exchange processes in the bulk air of the canopy as well as at foliage surfaces, and its application to prediction models. We have already demonstrated the usefulness of knowing the bulk air diffusivity coefficient for measuring flux intensities in stands. This parameter is an especially sensitive aerodynamic term defining the transport characteristics of the turbulent air. Knowledge of its correct quantitative value is indispensable to the correct measurement of canopy fluxes and the correct operation of prediction models for crop climate or crop processes. Figure 6-3 presents some relationships intended to demonstrate why this is so. Here are plotted various profiles for two crops quite distinctly different in geometric structure. The corn crop (Zea mays L.) example was $225 \mathrm{~cm}$ high with an LAI (leaf area index) of 4.3 while the contrasting or chardgrass (Dactylis glomerata L.) was $40 \mathrm{~cm}$ high with an LAI of 6.0. The foliage area density more appropriately defines the difference. In corn $F \approx 0.02 \mathrm{~cm}^{2} / \mathrm{cm}^{3}$ and in orchardgrass $\mathrm{F} \approx 0.2 \mathrm{~cm}^{2} / \mathrm{cm}^{3}$. The profiles were selected for a given time period near midday when the wind speed at the top of both crops was nearly the same. Insulation and soil moisture conditions were not sufficiently different to play a role. By normalizing both crops as to height, it is easier to demonstrate the absolute differences in profile characteristics. Notice first, that despite the fact that wind speed profiles are quite similar, there is an order of magnitude difference in the diffusivity values for the two crops; $\mathrm{K} \approx 2000 \mathrm{~cm}^{2} / \mathrm{sec}$ in corn and $200 \mathrm{~cm}^{2} / \mathrm{sec}$ in orchardgrass. The drag coefficients for the two crops also differed by an order of magnitude, $\mathrm{CD}=0.08$ for corn and 0.009 for orchardgrass. Thus there is a strong correlation between foliage area density, drag coefficient and the diffusivity.

As a result of the differences in aerodynamic properties of the two 

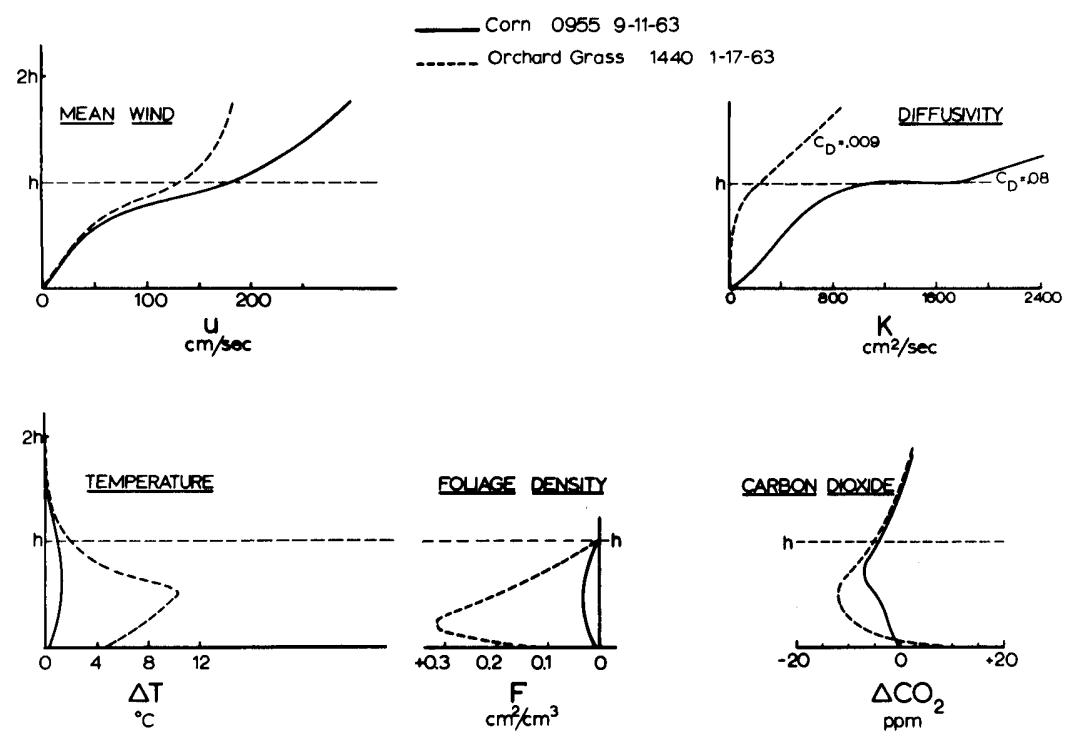

Fig. 6-3-Some comparisons between two crops differing widely in structure but under similar midday wind and radiation regimes on clear days. All comparisons made on a relative height basis where $h$ is the height of the crop.

crops there will be a marked difference in the climate in the two stands. Profiles of temperature and $\mathrm{CO}_{z}$ are the examples chosen. The trends are as one would anticipate but the magnitude is somewhat surprising. The maximum temperature of the air in the orchardgrass was almost $10^{\circ} \mathrm{C}$ greater than that of the air over the crop while in the corn the difference was of the order of $1-2^{\circ} \mathrm{C}$. The $\mathrm{CO}_{2}$ profile differences are not as marked, however. One can correctly conclude that a crop's structure definitely plays a role in controlling its own climate. Indirectly, structure effects can alter plant processes. For example, the temperature influences respiration.

It is rather difficult to demonstrate a coupling of stand structure on exchange rates, however, because of the multiplicity of feedback mechanisms involved. For example, with an increase in diffusivity, the $\mathrm{CO}_{z}$ differentials will decrease but other indirect effects will also take place, such as the lowering of leaf temperature and, maybe, an increase in evaporation rate. Still further, the conditions close to the leaf surface will undergo considerable change affecting the stomates or the exchange of gases through them. The complexity of these feedback mechanisms will always be the burr under the model-builder's saddle.

The site where interaction between the wind and leaf takes place is at the leaf surface. Figure 6-4 pictures the local situation at a leaf where the drag force is defined by the equation. The total force is related to the square of the wind speed, the area, the drag coefficient, and the density of the air. We will focus on the drag coefficient here. This parameter defines the ability of the surface to extract momentum from the wind stream thus creating turbulence to enhance mass diffusion. One can easily imagine that shape and size of the surface will play a 


\section{DRAG}

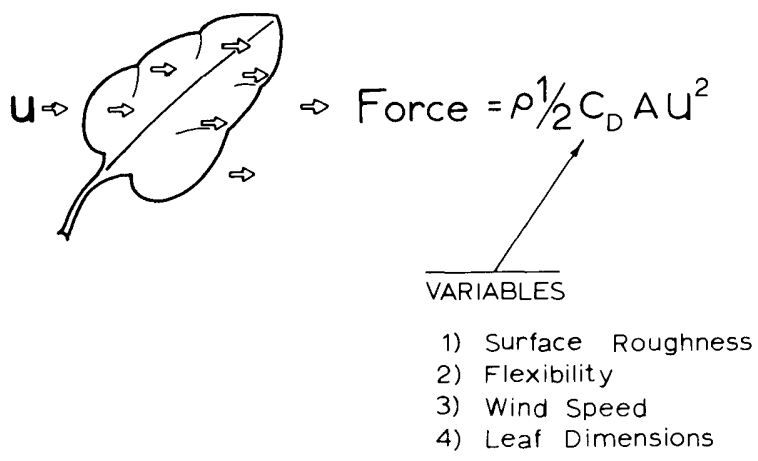

Fig. 6-4-Drag force at a leaf surface due to the wind, where $\rho$ is the density of the air, $\mathrm{C}_{D}$ is the drag coefficient, $A$ is the leaf surface area, and $u$ is the wind speed. Variables affecting $C D$ are listed.

role, as well as roughness and flexibility. In rigid bodies the drag coefficient will be independent of wind speed but in elastic bodies that bend, such as stems and leaves, the drag coefficient increases with increasing wind speed until streamlining occurs. To make matters even more complex, the interaction between the turbulence generated at one leaf surface on another nearby leaf surface, affects still further the drag coefficient. The complexity of distribution, shapes and size, roughness andflexibility of surfaces, and their interaction through and by the wind, precludes any simple understanding or model at present. A challenge is there!

Wright and Brown (1967) have evaluated the effect of wind and canopy structure on the drag coefficient in a corn crop. Figure 6-5 gives their

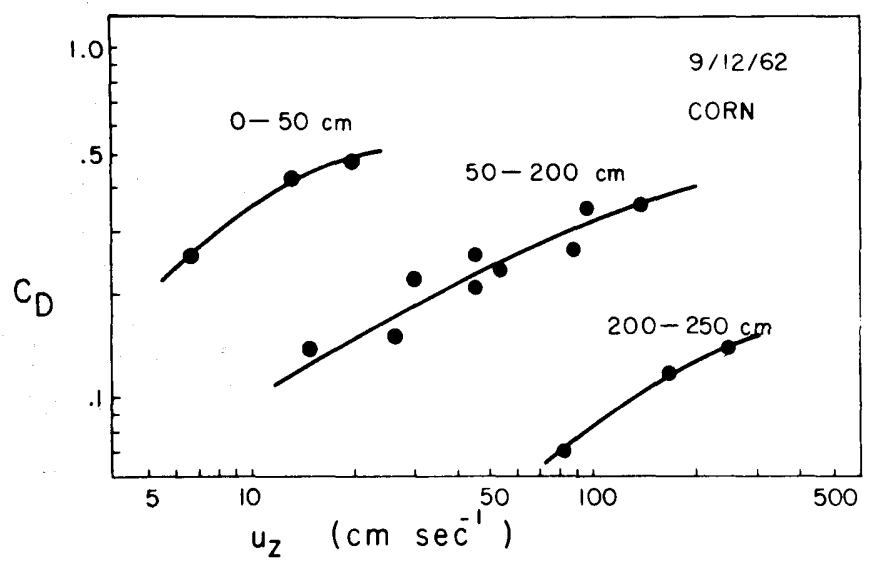

Fig. 6-5-Logarithmic plot of the local drag coefficient, $C_{D}$ as a function of wind speed for $50-\mathrm{cm}$ increments of height within a corn crop. From Wright and Brown (1967). 


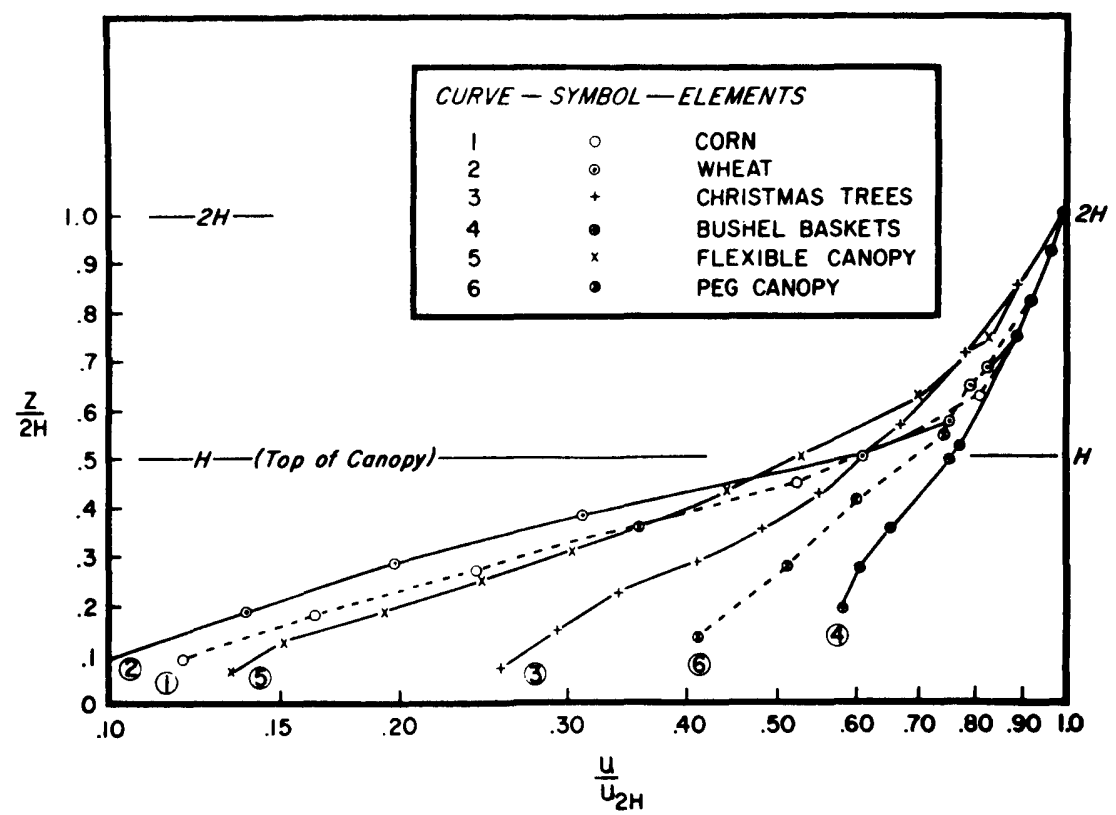

Fig. 6-6-Relative mean wind profiles for various "canopies" of relative height H. From Cionco (1967).

results. It is obvious that there is a coupling between wind speed and drag coefficient. They speculate that the depth effect in the canopy can be attributed to incorrectly judging the surface area of the tassel in the top layer and ignoring the soil surface influence in the bottom layer. All the points for the three midlayers of the stand fall on a common curve, however. This should be expected in corn because it is relatively uniform in the midstructure.

A manifestation of the coupling between wind and drag coefficient is found in the attenuation characteristics of the mean wind speed into flexible crops. Figure 6-6 gives normalized wind profiles as summarized by Cionco (1967). The shapes of the profiles in the stands are similar to light attenuation profiles and can be treated mathematically in the same way. One can characterize a profile shape by an attenuation or extinction coefficient. Cionco (1969) has done this for the same systems given in Fig. 6-6. Figure 6-7 shows Cionco's calculated attenuation coefficients as a function of wind speed for the several "crops." Notice that rigid, open systems, have low "a" or attenuation coefficient values that do not change with wind speed. On the other hand, more compact, flexible systems have higher "a" values that are sensitive to changes in wind velocity. All of these complexities associated with the coupling of wind and vegetation surfaces serve as a caution to those using the momentum balance approach to measure gaseous exchange in crop stands. This approach is not recommended for indiscriminate use, but it can be successfully used in uniform stands under steady winds, Lemon and Wright (1969). 

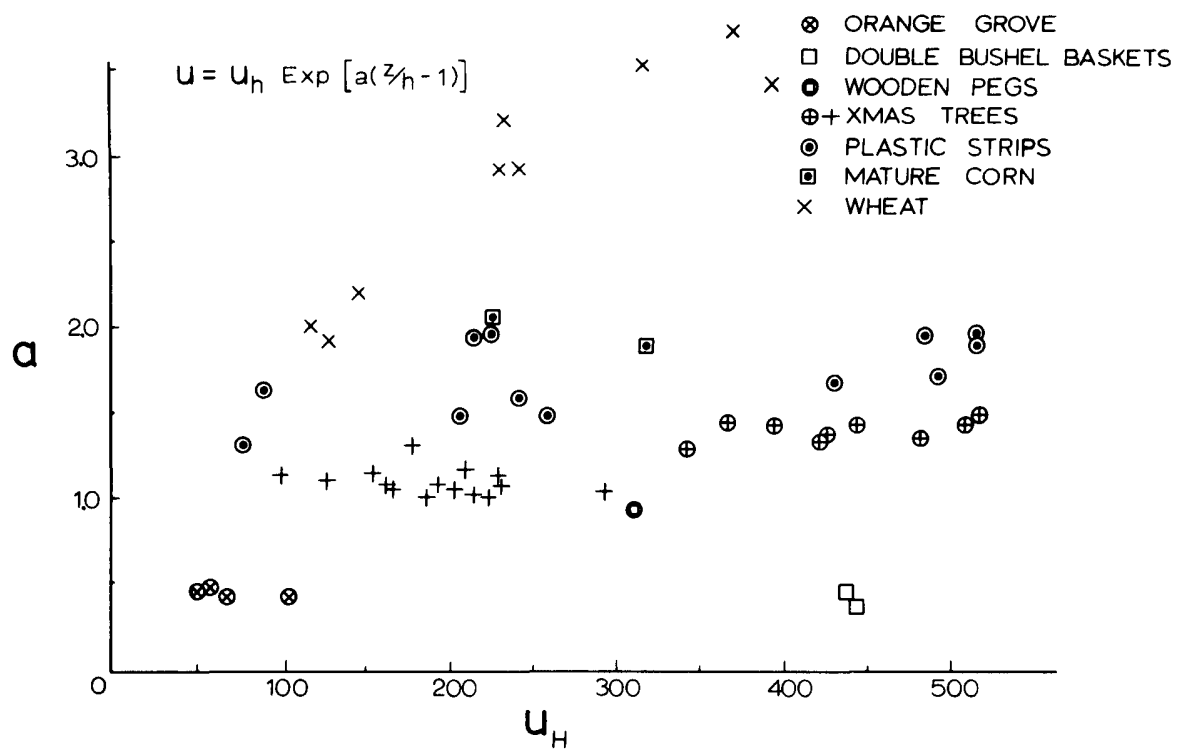

Fig. 6-7-Mean wind profile attenuation coefficient, a, plotted against mean wind speed $u_{H}$ at the top of various "canopies." From Cionco (1969).

People who have studied wind flow in forest canopies are now cautioning us about a common phenomenon, that we have not recognized too clearly in crop stands. This is wind "blowthrough" below the crown canopy. This is an acceleration in wind speed, creating "horizontal divergence" of momentum. Necessarily this also creates "horizontal divergence" of other atmospheric properties, too. How widespread this phenomenon is in agricultural crops is uncertain but open row crops and crops with distinct top canopies may be suspect. If this is a feature of a plant stand, then our present models cannot be used without considerable modification. Even the use of the classical log profile method for exchange calculation above the stand has to be treated with caution.

Figure 6-8 schematically presents an extreme case found in a tropical rain forest in Costa Rica by Lemon et al. (1969). One can see that there is a distinct "blowthrough" of wind under the crown canopy and a distinct "advection of $\mathrm{CO}_{2}$ " or horizontal divergence in the midlayer of the forest.

Special assumptions and unique applications of the momentum budget had to be used to evaluate the $\mathrm{CO}_{2}$ flux intensities through the various layers of the forest. Nonetheless, the end results of the calculations are reasonable. We shall discuss them later. Returning to Fig. 6-8, it is of interest to point out that the momentum "diffusing downward" from the top of the forest goes to zero where $\mathrm{du} / \mathrm{dz}$ goes to zero in the midpoint of the upper canopy. Therefore, log profile characteristics above the forest have relevance only to the top half of the upper canopy. Below this, the "blowthrough" phenomenon dominates the exchange processes.

Where do we stand today on simple mean wind velocity models for 


\section{$\mathrm{CO}_{2}$ FLUX MODEL}

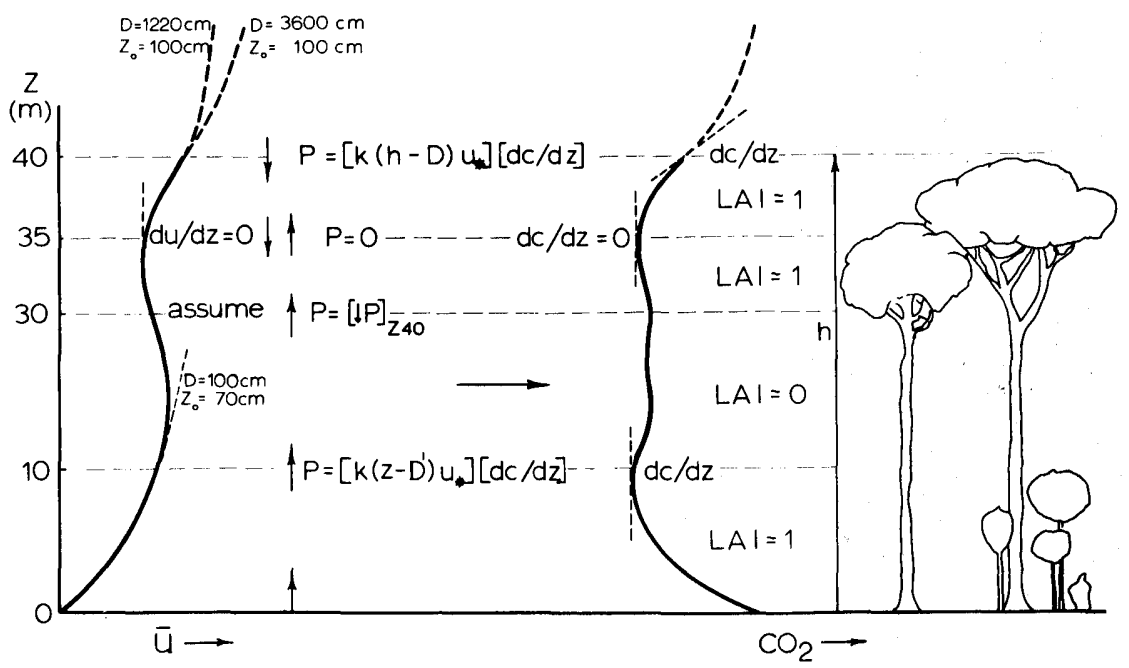

Fig. 6-8-Representative daytime wind speed, $\mathrm{u}$, and carbon dioxide, $\mathrm{CO}_{2}$, profiles in a tropical rain forest. From Lemon et al. (1969).

well-behaved uniform agricultural crops? Figure 6-9 points up some striking results recently reported by Ordway (1969) and Ordway and Groom (1969). Using computer techniques they tested more than 150 cases over a wide variation of input to evaluate two flow models, a Viscosity Model and Mixing Length Model. The test results for a corn stand are presented here. In the Viscosity Model test the momentum flux intensity $\tau$, or so-called Reynolds shearing stress, was assumed to be proportional to the wind speed gradient, du/dz, while $F$ and $K_{m}$ were adjusted. In the Mixing Length Model test, however, $\tau$ was assumed to be proportional to $(\mathrm{du} / \mathrm{dz})^{2}$, while $\mathrm{F}$ and $\mathrm{L}$ were adjusted. $\mathrm{L}$ is the Prandtl mixing length. The assumed distributions of $F, K_{m}$, and $\mathrm{L}$ to obtain the best fit of the models to actual cornfield data are presented. These assumed distributions are representative of the real world, however. In the Viscosity Model the best fit was obtained when the foliage area density, $F$, was assumed to be constant up to $\mathrm{z} / \mathrm{h}=$ 0.73 and then decreased linearly to zero at $h$, the height of the stand, along with assuming a linear increase of $\mathrm{K}_{\mathrm{m}}$ from 0 at $\mathrm{z}=0$. The goodness of fit between model points and experimental profile is perfect. Unfortunately an equally perfect goodness of fit was obtained with the Mixing Length Model when a constant distribution of $\mathrm{F}$ was assumed and $\mathrm{L}$ was assumed to be linear from 0 at $\mathrm{z}=0$ to $\mathrm{z} / \mathrm{h}=0.25$ and then constant to $h$. Amazingly both models give equally good results despite the fact that they are quite different physically. As Ordway understates, "This lack of discrimination, or uniqueness, leaves our understanding somewhat shaky." 
- VISCOSITY MODEL $\tau=\rho K_{m} d U / d z$
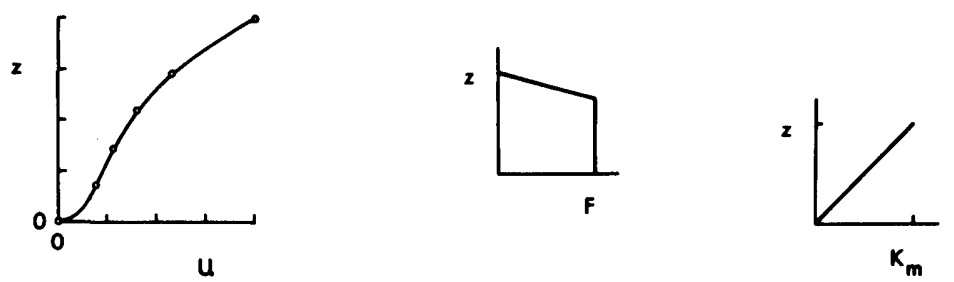

- MIXING LENGTH MODEL $\tau=\rho L^{2}(d U / d z)^{2}$
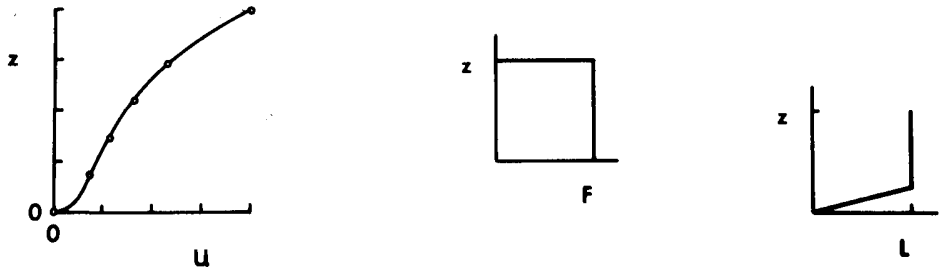

Fig. 6-9-Mathematical experiment for two theoretical wind profile models (see text). From Ordway (1969) and Ordway and Groom (1969).

\section{AGRONOMIC USEFULNESS OF MICROMETEOROLOGICAL STUDIES}

\section{A. As a Measuring Tool and the Pursuit of Understanding}

\section{Plant Growth}

In spite of the absence of sound physical models for predicting mean wind flow in crop stands, of the difficulty in measuring net radiation distribution in crop stands, and the need to assume constant drag coefficients in crop stands, progress has been made. In fact, 5 years ago we knew almost nothing about meteorological processes below the top of the crop. Today many of the physical processes and their coupling to plant characteristics are sufficiently well known that the modelbuilders are having a heyday. Progress on all fronts will pick up.

Viewed simply as a tool to measure the $\mathrm{CO}_{z}$ balance in several different kinds of plant communities, meteorological methods reveal quantitative likenesses and differences of interest. Attention is directed to Table 6-1 where relevant data are presented for a few forests and agricultural crops. These data are representative $\mathrm{CO}_{2}$ flux intensity values for clear days during the growing season. The values are for near midday and after darkness. The meteorological method used in each case is indicated, as is date and researcher. 


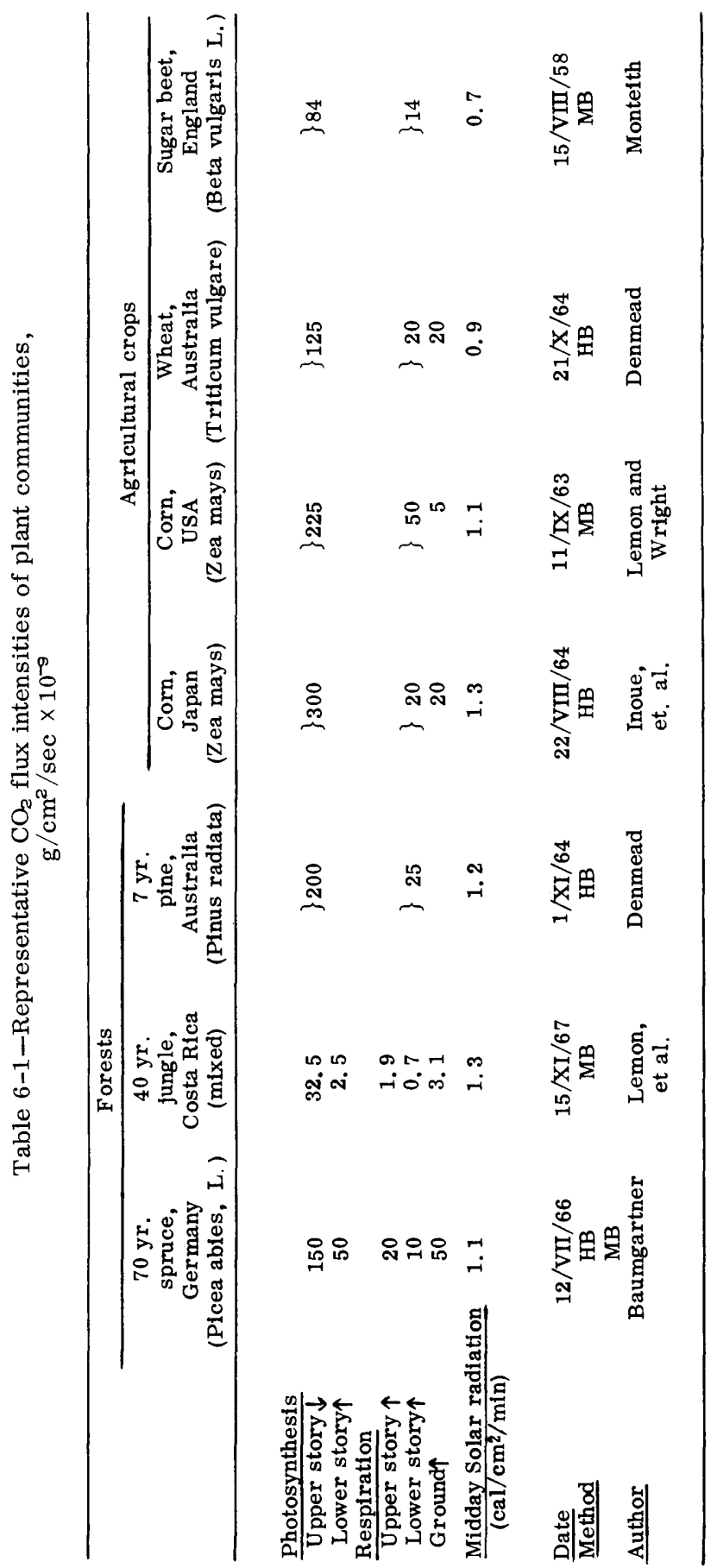


With study of Table 6-1 several points of interest emerge. Firstly, the photosynthesis rates of crops and forests are not uniquely different during the favorable part of the growing season when full canopy leaf development has been established. Secondly, the respiration rates of the canopies of crops and forests are not too different either. Thirdly, the respired $\mathrm{CO}_{2}$ evolved from the ground surface is quite variable. It is highest from the temperate region spruce forest and lowest in the tropical region rainforest. In our own studies in corn we have observed wide variation in the apparent evolution of $\mathrm{CO}_{2}$ from the ground. Two variables seem operative, time of growing season and wetness of soil. The time of the season effect is not related to soil temperature.

Monteith and Szeicz (1960) mention similar seasonal fluctuations in a field of sugar beets. Values for our corn in Table 6-1 and those for sugar beets were taken in times of evident low ebb.

While it may be questionable to make an efficiency ranking of the different systems, based on the figures given in Table 6-1, such a ranking may in fact be realistic. The method of ranking was this: First, all the photosynthesis gains in Table 6-1 were adjusted to a common radiation base $\left(1.0 \mathrm{cal} / \mathrm{cm}^{2} / \mathrm{min}\right)$ assuming proportional response, then the total respiration losses of both ground and canopy were deducted. The highest net value is considered associated with the most efficient plant community. Their ranking from high to low is: corn (Japan), corn (USA), 7-year Pinus radiata forest (Australia), sugar beet (England), wheat (Australia), 70-year spruce forest (Germany), and 40-year tropical rain forest (Costa Rica). This ranking only holds for the conditions of midgrowing season after full leaf development. While a highly selected tropical grass leads the listing, the other cultivated agricultural crops show no evident superiority to the forests. The tropical jungle however is definitely the lowest.

No doubt, on a yearly basis the difference between the tropical forestproductivity and the temperate forest productivity would equalize somewhat because the jungle never rests. Of more profound importance to this symposium emerges the realization that highly selected agricultural crops may be no more efficient in their photosynthesis and respiration processes than less highly selected plant communities such as forests. Man's manipulation of plant materials for production has not resulted in increasing the efficiency of the photosynthesis or respiration processes per se but rather has further channeled the products of photosynthesis into harvestable items.

2. Used as a Tool to Pinpoint Critical Plant-Environmental Interactions

Because plants are so "plastic" and so beautifully integrate the variables of the environment into smooth growth curves over days, or weeks, or seasons, classical growth analysis over days, or weeks, or seasons can hope at best to evaluate only the most pronounced features of the environment affecting plants, such as sunlight or extremes of temperature and moisture. Plant-to-plant variation in the field also presents a tremendous sampling problem.

Thus there would appear to be advantages to using gas exchange 
methods to measure plant growth and environmental interaction on a short-time basis. Indeed use of the methods discussed here have pinpointed interesting interactions; for example, the short-time intermittent cloud and sunshine influence on sunlight utilization in corn discovered by Denmead (1966). Because of the response time characteristics of stomates closing and opening. and the time scale of sunshine and intermittent cloud passage, a cornfield in Iowa used sunlight less efficiently on the day with intermittent sun than on a clear day. Another example, less clearly defined, is the apparent influence of wind on the utilization of sunlight by corn in the field on bright days. Lemon (1963) and Wright and Lemon (1966) and Denmead (1966) have reported an increase in $\mathrm{CO}_{2}$ exchange rate with increasing wind. They speculate that this is due to increased $\mathrm{CO}_{2}$ concentration at the immediate leaf surface through the influence of increasing wind turbulence favorably altering the immediate leaf boundary layer. This has to be speculation, however, because increasing wind alters temperature and humidity relationships as well as the frequency distribution of light in a flexible canopy. Perhaps the simple mechanical movement of the leaves influence the stomates?

In any event the number of inter locking relationships between plants and the environment in time and space are infinite if one recognizes the dynamics involved. Take on the one hand, as an example, the whole hierarchy of temperature fluctuations in the environment from a seasonal scale to the scale of fractions of a second. Now consider on the other hand, the lag time, the feedback, the hysteresis in the multiple control systems sensitive to temperature in the plant. On top of all this, remember the wide variation in plants and the potential for manipulation. It seems that the future will always bring us a new array of plant environment interactions requiring study and understanding. We'll never run out. This applies to temperature, soil nutrition, sunlight capture, or what have you.

Where do we stand today facing these complexities? Of one thing we are sure, the physiologist and his growth chambers has to be linked, with leg irons if necessary, to the meteorologist and his outdoor studies. The latter has to define causes and frequency of environmental variation and the former has to interpret response in the plants.

People talk of "climatic noise" for the relatively short time variation in the climatic elements, perhaps on the scale of day-to-day, hourto-hour, maybe even second-to-second. The title "noise" may be appropriate, if these variations are just minor background to the big events. We simply don't know. There is a challenge!

I'd like now to briefly discuss some of our recent studies at Ithaca defining some of the very short-time environmental variation attributable to local turbulence. First, we have to give a qualitative description of turbulence and an "eddy." Figure 6-10 borrowed from Ordway (1969) is very helpful. In the lower left is depicted a section of a large forest with the wind blowing from left to right. The mean wind, $u$, above the stand is indicated by the large horizontal arrow. The profile of the mean horizontal flow of wind in the stand is sketched in part on the right. Far from the edges of the forest with adequate fetch this mean wind profile will be the same everywhere. Superimposed on this mean 

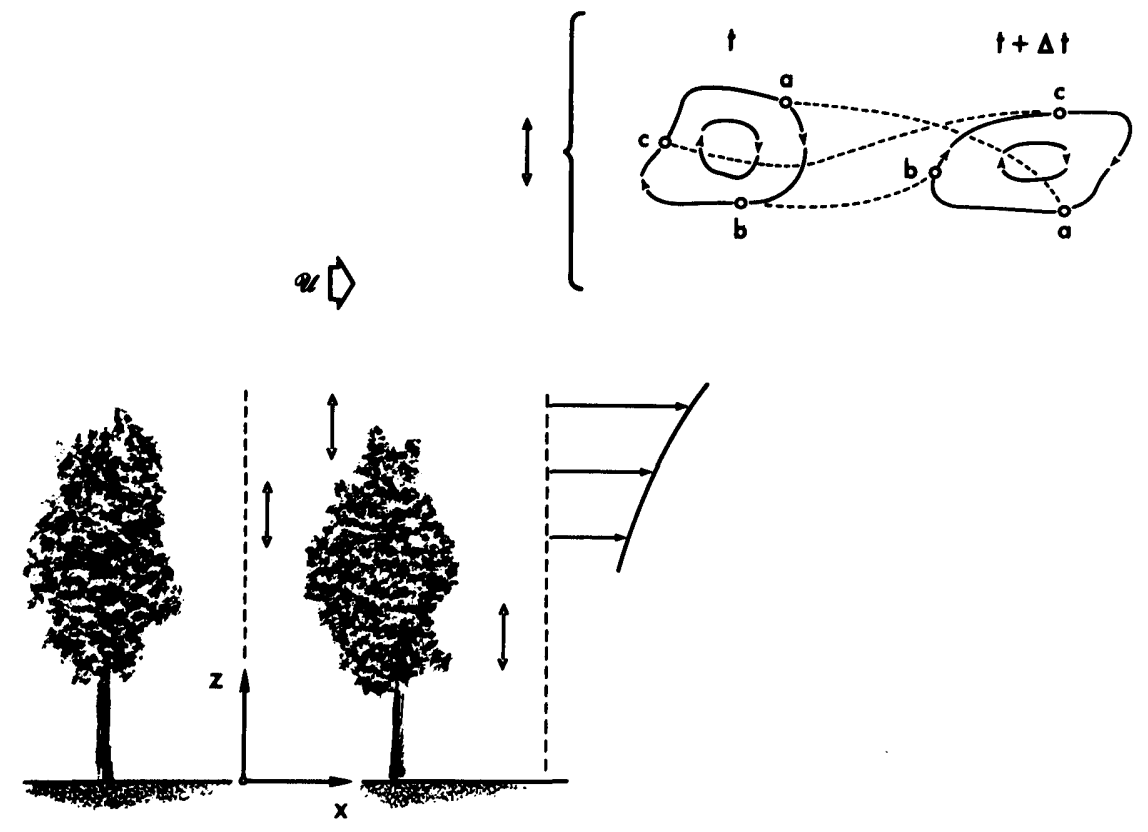

Fig. 6-10-Idealized wind flow characteristics in a forest stand. Horizontal arrows indicate mean horizontal wind flow. Vertical arrows indicate vertical wind flow due to turbulent motion of "eddies" between time $t$ and $t+\Delta t$ (see text).

windflow will be a variation in velocity associated with turbulence. Turbulence is a fluid dynamic instability caused by two mechanisms:

1) Thermal effects causing density variation in the air, thereby creating additional fluid motion. This is common where surfaces are heated by sunlight and then adjacent air is heated in turn. This less dense air will rise in globs we call eddies, being replaced by sinking cooler, denser globs or eddies. Such "buoyancy" effects will impart vertical motion to the mean flow, diffusing physical properties of the air down vertical gradients.

2) Frictional effects caused by wind flow over rough surfaces together with the excessive Reynolds Number that must be sustained. The Reynolds Number is defined as the ratio of inertial forces to the viscous forces of flow. For typical wind speeds and roughness elements in our crop stands, the Reynolds Number will be of the order of $10^{6}$ or greater, sufficiently large to classify such a system as a turbulent regime. Paraphrasing Schlichting (1955), "The most striking feature of turbulent motion is the fact that the velocity and pressure at a fixed point in space do not remain constant with time but perform very irregular fluctuations of high frequency. The lumps of fluid which perform such fluctuations in the direction of flow and at right angles to it do not consist of single molecules as assumed in the kinetic theory of gases. Instead they are macroscopic fluid balls of varying size, superimposing their own intrinsic motion on the mean flow. The size of the balls which 


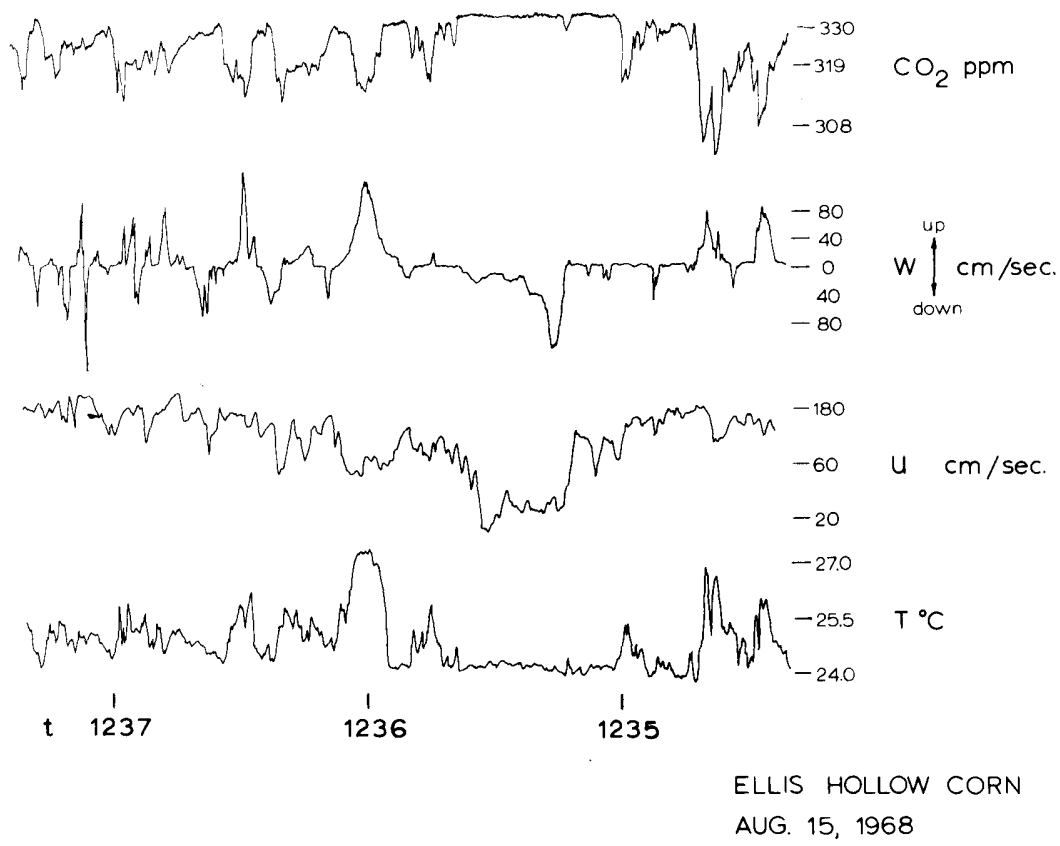

Fig. 6-11-Short-time variation of some climatic properties of the air flowing $2 \mathrm{~m}$ above an actively-growing cornfield during the midday period 1234 to 1237 EST. Air properties indicated are: carbon dioxide, C; vertical wind speed, w; horizontal wind speed, $\mathrm{u}$; and temperature, T. From Desjardins (personal communication).

continually agglomerate and disintegrate is determined by the scale of the associated geometric boundaries, whatever they may be."

In Ordway's figure (Fig. 6-10) the turbulent fluctuations in the forest are the double-pointed arrows at right angles to the mean wind flow. The upper right corner diagram amplifies the significance of the vertical arrows. This pictures an eddy as it moves from left to right in the period, $t$ to $t+\Delta t$ and in the same period rotates in the direction of the arrows. By tracing the trajectories of the three particles in the fluid ball, a, b, and c over the period, it is apparent that the criss-crossing of the paths produce the characteristic upward and downward motion that is responsible for vertical diffusion in a horizontal flow.

One eddy to the next will also have different physical properties. One may be hotter or colder than another, one may be wetter or drier than another and/or richer or poorer in $\mathrm{CO}_{2}$. Figure 6-11 taken from Raymond Desjardins' thesis research demonstrates this beautifully. (To be submitted in partial fulfillment of the requirements of the Ph.D. degree at Cornell University.) The continuous traces over a shorttime period give the wind stream variation in $\mathrm{CO}_{2}, \mathrm{C}$, vertical wind speed, w, horizontal wind speed, $u$, and temperature $T$. These were obtained on a clear day about $2 \mathrm{~m}$ above our Ellis Hollow cornfield when the corn was growing rapidly. 
Casual inspection reveals a correlation between all elements, but less so for the horizontal wind. Further study reveals that "up drafts" are associated with an increase in temperature and a fall in $\mathrm{CO}_{2}$. Evidently eddies coming up from the crop are hotter, indicative of warmer surfaces. Their lower $\mathrm{CO}_{2}$ content is indicative of photosynthesis sinks in the stand. "Down drafts" are associated with cooler eddies which are also richer in $\mathrm{CO}_{2}$. Up drafts appear to be "stronger" and associated with a decrease in mean wind flow. Up drafts may be stronger too because they were measured relatively near the surface and appear less frequently yet persist for shorter periods of time. Major variations appear to be of the frequency of 2 to 4 cycles $/ \mathrm{min}$. Amplitude is $3-5^{\circ} \mathrm{C}$ in air temperature and $10-20 \mathrm{ppm}$ in $\mathrm{CO}_{2}$. The wind component amplitudes are about $\pm 80 \mathrm{~cm} / \mathrm{sec}$ for vertical wind and $50-100 \mathrm{~cm} / \mathrm{sec}$ horizontal wind speed.

Without further analysis not much can be said about the mechanisms creating the eddies in the cornfield. Both thermal and frictional effects are undoubtedly at work. An analysis of the frequency distribution of the eddies will eventually throw light on their origins. Allen (1968) has made such an analysis for another plant stand.

Figure 6-12 from Allen's work gives the relative contribution to the total variance of horizontal wind speed as a function of frequency at which the variation occurs. Six levels are shown for a 30-year-old Japanese larch forest (Laris leptolepis L.).

The spectrum of wind speed variations is expressed on a cycle per

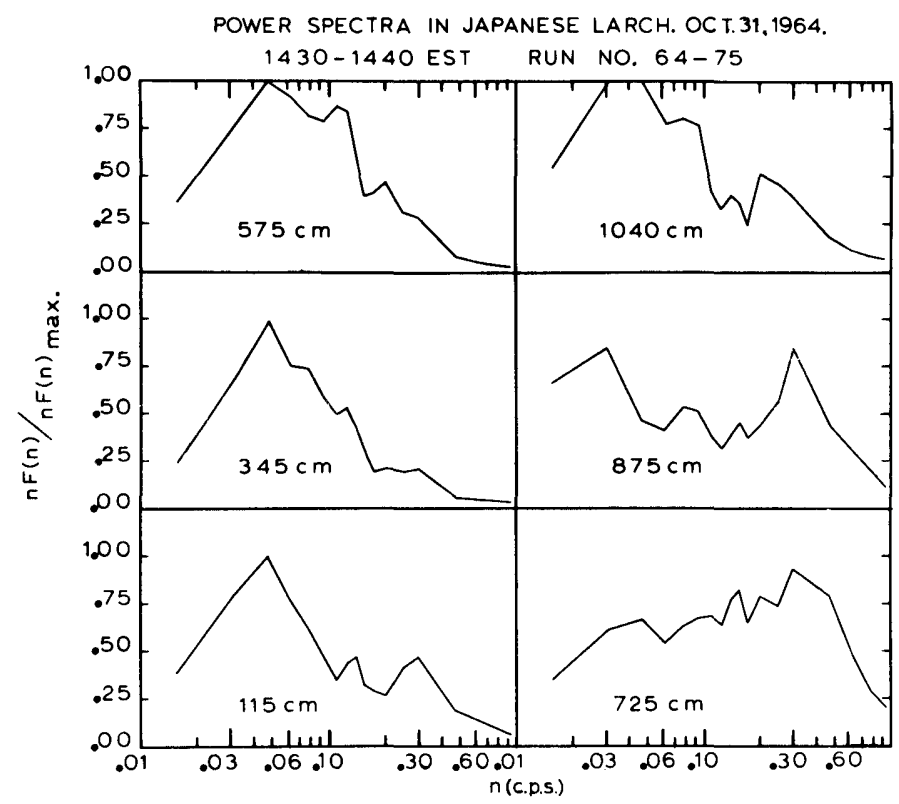

Fig. 6-12-Composite, normalized power spectra of the wind at the indicated heights in a Japanese larch forest near Ithaca, N. Y. From Allen (1968). 
second basis and the relative energy distribution of the variation at each frequency is expressed as a fraction of the maximum energy at some frequency. The forest was $1,040 \mathrm{~cm}$ high. The top one-third of the for est consisted of conical tree tops and was fairly open in contrast to the middle one-third which was quite dense. The lower one-third was somewhat more open, consisting of many needle-less dead branches. In each of the six power spectra presented there is a pronounced low frequency peak at about 0.04 cycles $/ \mathrm{sec}$ corresponding to a period of 20 to $25 \mathrm{sec}$. With a wind speed about 350 to $375 \mathrm{~cm} / \mathrm{sec}$ at $1,569 \mathrm{~cm}$ above the ground, the low frequency peak is associated with gusts or eddies of about $70-100 \mathrm{~m}$ wavelength. Near the forest floor at a height of 115 $\mathrm{cm}$ there appears to be very little high frequency variance. This can be interpreted to mean that there is less turbulence on a small scale and most of the variation is due to large eddies. A scale of 70-100 $\mathrm{m}$ for these large eddies might be associated with topographic features of the landscape but definitely not the local vegetation. On the other hand, further up into the vegetation more high frequency peaks develop in the spectra. Peaks in the 3-7 sec period range, with wind velocities at about $100 \mathrm{~cm} / \mathrm{sec}$, are indicative of eddies on the scale of the individual trees which were planted on a $3-4 \mathrm{~m}$ grid. At height $725 \mathrm{~cm}$ the vegetation was densest. Fluctuation periods in the high frequency range here had a period of $3 \mathrm{sec}$. With an average wind of $60 \mathrm{~cm} / \mathrm{sec}$ at this level, the eddy scale becomes $180 \mathrm{~cm}$. Unfortunately, response time characteristics of the measuring system filtered out the very high frequency components, so we have no idea of their relative contributions. Nonetheless there is reason to believe that Allen's spectra cover much of the eddy scale that significantly contributes to climatic variation up to 10-min periods.

What can we deduce out of all this? For one thing the meteorologists have made a beginning to understand the sources of climate variation due to local turbulence. But, in addition, we need to know which physiological processes have a response time comparable to these short-time variations in climatic elements. Perhaps there are none. We do know that stomates respond to variation in the environment on the scale of 1-30 min. Variations due to local eddies of the scale discussed here are too short-lived to be of significance to stomates, or it would seem so.

In the study of exchange rates, people like Desjardins are taking advantage of the eddy structure and its vertical transport properties to measure, on a very short-time scale, the flux intensity of $\mathrm{CO}_{2}$. Once these tools are developed and the tremendous data-handling problems solved, short-time crop response in the order of minutes will be measurable in the field.

\section{Model Building and Testing}

One of the ultimate objectives of making measurements in the pursuit of understanding is the development of prediction models. Models may be used to predict crop response, to predict crop climate and water use. Inherent in these models will come the ability to optimize architectural design or crop geometry, to predict new crop performance in 
a given climate regime and further suggest favorable management practices. Naturally models have to be crude at first, representing the level of understanding at the time. They evolve into more complex (or simpler) ones as understanding increases, coming closer and closer to representing reality. While I have stressed, in this presentation, some of the weak spots in our understanding of the aerodynamic exchange processes, it would be wrong to leave a pessimistic impression.

As a note of optimism, I would like to emphasize the progress we have made in understanding the meteorology involved in $\mathrm{CO}_{2}$ exchange in crops. This is best illustrated by Fig. 6-13 from Lemon and Wright (1969). In this figure we have light response curves, presented on a leaf area basis, determined by the momentum balance method of measuring $\mathrm{CO}_{3}$ exchange in a cornfield. Each experimental point is a "mean value"for a unit leaf area in a given $25-\mathrm{cm}$ leaf layer in the crop at the indicated time of day. The highest points are for the top $25-\mathrm{cm}$ layer, the next highest point for the second $25-\mathrm{cm}$ layer from the top, and so on downwards. Encouraging is the fact that the light response curves approach and look very similar to those determined by my colleague, Dr. Musgrave, using a plastic chamber gas exchange technique in the field. However, they are not quite alike. They should not be on two counts at least. First of all, the crop structure-light interaction would have to be correctly taken into account. For example, randomness of leaf angle distribution in each layer as well as frequency distribution of light intensity in each layer would have to be evaluated in a "correct"

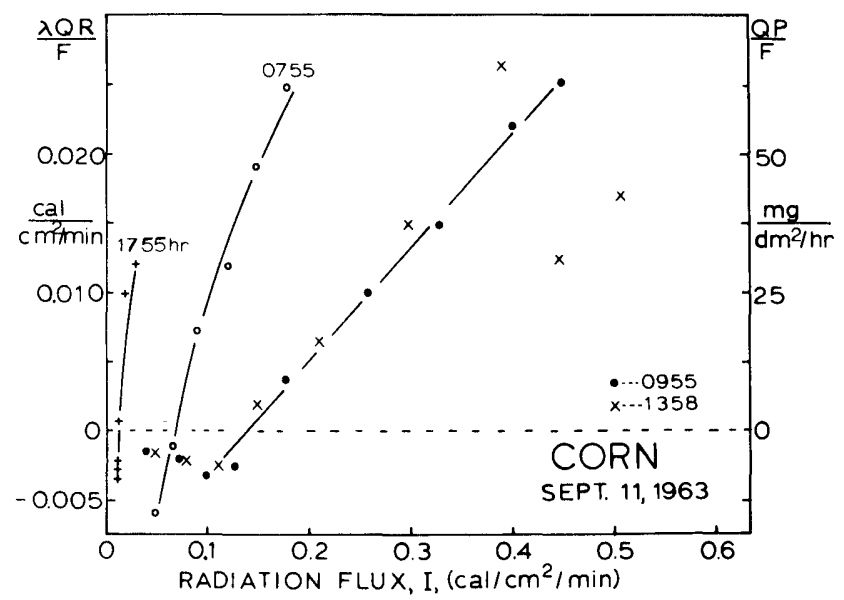

Fig. 6-13-Light response curves for corn plant community as indicated by hour. Radiation flux is incident intensity $(0.3-0.7 \mu$ wavelength). Photosynthesis and respiration expressed on a leaf area basis as $\mathrm{CO}_{2}$ exchange or energy equivalence. Each point at a given hour represents a given leaf level in the canopy beginning with the top leaves at $225 \mathrm{~cm}$ at the highest radiation intensity and progressing downwards into the canopy in $25-\mathrm{cm}$ increments with decreasing radiation. Not all 1755 and 0755 points near the bottom of the canopy are plotted. Each point is the "mean" response of all leaves at a given level. E1lis Hollow, N. Y. Sept. 11, 1963. 
light response model for plant communities. Second, other community structure effects would have to be evaluated as well. For example, supply of $\mathrm{CO}_{z}$ at each layer, in addition to temperature effects at each layer. This all could be tested provided we accepted in the very beginning that the original measurements and assumptions in the momentum budget were all correct. So this brings us to the conclusion that we have made progress in view of the "reasonable" results given in Fig. 6-13, yet proof of correctness presents very real complexities. We can turn the coin over and say, too, that testing of light models will prove equally complex by the same line of reasoning. Models, however, are very useful tools, as Dr. Waggoner demonstrates in this symposium (Chapter 15, this book). His modeling is an excellent step forward, yet our work on the physics of the environment and the physiology of plants is not finished.

\section{LITERATURE CITED}

Allen, L. H., Jr. 1968. Turbulence and wind speed spectra within a Japanese larch plantation. J. Appl. Meteorol. 7:73-78.

Baumgartner, A. 1969. Meteorological approach to the exchange of $\mathrm{CO}_{2}$ between the atmosphere and vegetation, particularly forest stands. Photosynthetica (Czechoslovakia) 3:127-149.

Begg, J. E., J. F. Bierhuizen, E. R. Lemon, D. K. Misra, R. O. Slatyer and W. R. Stern. 1964. Diurnal energy and water exchanges in bulrush millet in an area of high solar radiation. Agr. Meteorol. 1:294-312.

Brown, Kirk W., and Winton Covey. 1966. The energy-budget evaluation of the micrometeorological transfer processes within a cornfield. Agr. Meteorol. $3: 73-96$.

Cionco, R. 1967. Flow characteristics and mathematical modeling of canopy regimes. Proc. Tech. Exch. Confer. AWS Tech. Report 196, p. 260-1. Published by Air Weather Service (MAC), U. S. Air Force.

Cionco, R. 1969. Some aspects of airflow characteristics of simple canopies. J. Appl. Meteor. (In preparation).

Denmead, O. T. 1964. Evaporation sources and apparent diffusivities in a forest canopy. J. Appl. Meteorol. 3:383-389.

Denmead, O. T. 1966. Carbon dioxide exchange in the field; its measurement and interpretation. Proc. WMO Seminar on Agricultural Meteorology, Australia, p. 445-482.

Denmead, O. T. 1969. Comparative micro-meteorology of a wheat field and a forest of Pinus radiata. Agr. Meteorol. (in press)

Inoue, E., Z. Uchijima, T. Udagawa, T. Horie, and K. Kobayashi. 1968. Studies of energy and gas exchange in crop canopies (2) $\mathrm{CO}_{2}$ flux within and above a corn plant canopy. J. Agr. Meteorol. (Japan) 23:165-176. [In Japanese with English Summary]

Lemon, Edgar. 1963. Energy and water balance of plant communities, p. 55-78. In L. T. Evans (ed.) Environmental control of plant growth. Academic Press Inc., New York.

Lemon, Edgar. 1967. Aerodynamic studies of $\mathrm{CO}_{2}$ exchange between the atmosphere and the plant, p. 263-290. In A. San Petro, F.A. Greer, and T.J. Army (ed.) Harvesting the sun: Photosynthesis in plant life. Academic Press, New York.

Lemon, E. R., and J. L. Wright. 1969. Photosynthesis under field conditions. XA. Assessing sources and sinks of carbon dioxide in a corn crop using a momentum balance approach. Agron. J. 61:405-411. 
Lemon, Edgar, L. H. Allen, Jr., and Ludwig Muller. 1969. Photosynthesis in a tropical rain forest. II. Vertical carbon dioxide fluxes. Science (in preparation).

Monteith, J. L., and G. Szeicz. 1960. The carbon dioxide flux over a field of sugar beets. Quart. J. Royal Meteorol. Soc. 86:204-214.

Ordway, D. E. 1969. An aerodynamicist's analysis of the Odum cylinder approach to net $\mathrm{CO}_{2}$ exchange. Photosynthetica (Czechoslovakia) 3:199-209.

Ordway, D. E. and M. A. Groom. 1969. Wind Profile Prediction: Basic formulation and mathematical experiment. J. Appl. Meteorol. (In preparation).

Schlichting, H. 1955. Boundary layer theory. Pergamon Press, N. Y. p. 370384.

Wright, J. L. and K. W. Brown. 1967. Comparison of momentum and energy balance methods of computing vertical transfer within a crop. Agron. J. 59: 427-432.

Wright, J. L. and E. R. Lemon. 1966. Photosynthesis under field conditions. IX. Vertical distribution of photosynthesis within a corn crop. Agron. J. 58:265268.

Uchijima, Z. 1962a. Studies on the microclimate within plant communities.

(1) On the turbulent transfer coefficient within plant layers. J. Agr. Meteorol. (Japan) 18:1-9.

Uchijima, Z. 1962b. Studies on the microclimate within plant communities.

(2) The scale of turbulence and the momentum transfer within plant layers.

J. Agr. Meteorol. (Japan) 13:58-65.

\title{
6... DISCUSSION
}

\author{
O.T. DENMEAD
}

CSIRO Division of Plant Industry

Canberra, Australia

I will confine my remarks to two points of methodology.

The first concerns the relationships between the eddy diffusivities for heat, water vapor, $\mathrm{CO}_{2}$ and momentum and some practical consequences for field measurements of $\mathrm{CO}_{2}$ exchange. Dr. Lemon has indicated that the eddy diffusivity for $\mathrm{CO}_{2}$ is commonly assumed equal to that for heat and water vapor, or momentum. Similarity between the diffusivities can be tested in the following way:

Consider the vertical flux of any transported entity whose concentration at height $\mathrm{zi}_{i}$ is $\mathrm{si}_{i}$. It can be shown that above the crop, where the fluxes that interest us are constant with height, 


$$
\frac{s_{1}-s_{2}}{s_{1}-s_{3}}=\frac{\int_{z_{1}}^{z_{2}} K^{-1} d z}{\int_{z_{1}}^{z_{3}} K^{-1} d z}
$$

in which $\mathrm{K}$ is the appropriate eddy diffusivity. By comparing ratios of concentration differences for the various entities, we can make some assertions about their diffusivities.

Figure 6D-1 presents comparisons of this type for the transport of heat, water vapor, momentum and $\mathrm{CO}_{2}$ above a sward of turf. The observations were made over a wide range of stabilities as indicated by the Richardson Numbers shown in the figure. There is some scatter in the observations but this is within the expected errors in measurement, and the data generally conform to the hypothesis that the eddy diffusivities are the same for all entities, or at least in some constant ratio to each other.

It should be pointed out that the measurements shown in Fig. 6D-1 were made very close to the surface. There is evidence, e.g., Swinbank

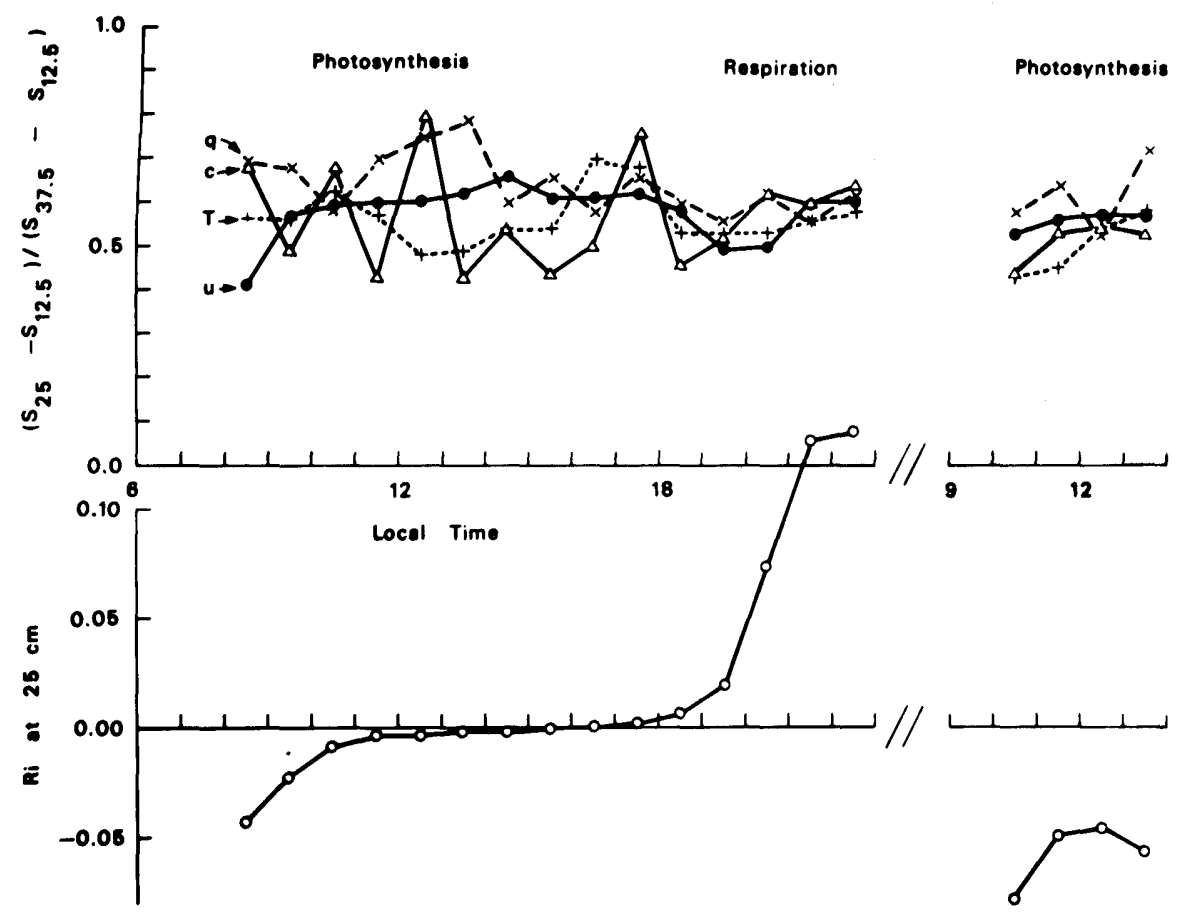

Fig. 6D-1-Top: Comparison of difference ratios for specific humidity $\mathrm{q}, \mathrm{CO}_{2}$ concentration $\mathrm{c}$, temperature $\mathrm{T}$ and horizontal wind speed $\mathrm{u}$ over grass. Bottom: Richardson Number at $25 \mathrm{~cm}$. 
and Dyer (1967), that at larger distances from the surface there is still similarity between the diffusivities for heat and matter, but not between them and the diffusivity for momentum.

These possible differences in transport mechanisms, combined with height limitations due to insufficient fetch (for which it appears from many investigations (e.g., Bradley, 1968) that a suitable fetch to heightabove-surface ratio might be as much as 200:1], mean that in both heat budget and momentum budget approaches, measurements above the canopy will usually have to be restricted to a region close to the surface. In these circumstances, accurate measurements of the small differences in $\mathrm{CO}_{2}$, temperature, humidity, and wind velocity which exist, test the capabilities of most instruments, particularly those now used for $\mathrm{CO}_{z}$ measurement. Thus, instrumental errors alone will of ten limit the accuracy of gas exchange measurements above the canopy to $5 \%$ to $10 \%$.

Within the canopy, quite apart from any considerations of similarity between the diffusivities, procedures for estimating fluxes require estimates of the gradients of the various entities. I don't share Dr. Lemon's belief that forming the gradients "is not too difficult." Differentiating experimental data usually is. Our experience is that computational and instrumental errors can easily introduce uncertainties in these withincanopy flux estimates of $20 \%$.

My purpose in making these remarks is to point out that although micrometeorological measurements of $\mathrm{CO}_{2}$ exchange provide us with a valuable tool for studying photosynthesis in the field and for rationalizing plant-environment interactions, we should not expect too much of them. They may not be able to detect a difference of $10 \%$ or less in $\mathrm{CO}_{2}$ exchange, which the practical agronomist would consider of significant economic value.

My second point concerns the use of the heat budget method. Dr. Lemon has pointed out the difficulty in obtaining suitable spatial and time averages of net radiation. We have been tackling this problem by the use of strip net radiometers (Denmead, 1967) to obtain line averages of the net radiation at appropriate levels in the canopy. The instrument can be expected to have an azimuthal error but tests which we have made indicate that for most times of day, this is within acceptable limits.

Following Dr. Lemon's development of the energy balance equation (contained in his Fig. 6-1), and defining the equivalent temperature $\theta$ as $\mathrm{T}+\mathrm{L} \rho_{\mathrm{w}} / \rho c_{\mathrm{p}}$, we have that

$$
K=\frac{R_{N}-G}{\rho c_{p} d \theta / d z} .
$$

$\theta$ is normally a slowly varying, monotonic function of $z$ so that $d \theta / d z$ can be calculated with small error. This method of arriving at $\mathrm{K}$ seems to me to have a number of advantages over the momentum balance approach. First, the calculation of $\mathrm{K}$ is less prone to computational errors. Second, insofar as steady-state conditions prevail and there is similarity between the diffusivities, the formulation of $\mathrm{K}$ is exact; no assumptions are needed about the relation between drag coefficients, 
foliage geometry, and wind speed. Third, the method does not require specification of the foliage distribution. Finally, the method has a bonus since the measurements needed for the calculation of $\mathrm{K}$ also yield the evaporation profile within the canopy, and in most investigations of plant growth processes in the field, we are not only interested in the distribution of the sources and sinks for $\mathrm{CO}_{2}$, but also in the corresponding distributions for water vapor and heat.

This is not to discount the importance of understanding the "aerodynamics" of crops, to which Dr. Lemon and his colleagues have contributed so substantially. I believe, however, that further progress in this field will require both controlled studies in properly constructed wind tunnels in which the structure of turbulence within plant canopies can be modelled successfully, and elaborate studies in the field with appropriate fast-response sensors small enough not to disturb the canopy and cheap enough to sample at many points.

\section{LITERATURE CITED}

Bradley, E. F. 1968. A micrometeorological study of velocity profiles and surface drag in the region modified by a change in surface roughness. Quart. J. Roy. Meteorol. Soc. 94:361-379.

Denmead, O. T. 1967. A strip net radiometer. Aust. J. Instr. Control 23:61. Swinbank, W. C., and Dyer, A. J. 1967. An experimental study in micrometeorology. Quart. J. Roy. Meteorol. Soc. 93:494-500.

\section{6...DIscussion}

\section{PIETER GAASTRA}

Centre for Plantphysiological Research

Wageningen, The Netherlands

Dr. Lemon has presented an excellent review of aerodynamic principles governing gaseous exchange in crop stands. As an agronomistplant physiologist I would like to present some of my conclusions about some aspects of $\mathrm{CO}_{2}$-exchange in crop canopies.

1) Table 6-1 in Lemon's paper shows that the $\mathrm{CO}_{\mathbf{a}}$-flux from the soil can be of similar magnitude as the $\mathrm{CO}_{z}$-uptake by the crop. This is a complicating factor for the aerodynamic methods of measuring crop canopy photosynthesis. It does not mean, however, that soil respiration can appreciably enhance crop photosynthesis. This is shown by the data in Fig. 6-3 of Lemon's paper. Canopies with very different geometric canopy structures (corn and orchardgrass) show distinct differences in diffusivity values and drag coefficients, but for both crops the $\mathrm{CO}_{2}$ - 
gradients are similar and small. This suggests that the $\mathrm{CO}_{2}$-transport resistance in the air between the plants is small as compared with the boundary layer resistances and internal resistances of the leaves. Another conclusion is that $\mathrm{CO}_{z}$-fertilization usually cannot be profitably applied in the field.

2) Although differences in crop structure probably have a small effect upon photosynthesis through $\mathrm{CO}_{2}$-concentration, crop structure can strongly affect plant temperature and transpiration rate. In this way, photosynthesis can be correlated with stand structure, and Lemon has rightly stated that the multiplicity of feedback mechanisms involved make it difficult to demonstrate a coupling of structure on exchange rates. Certainly, for the model builder, insight in principles governing exchange rates is extremely important. Equally important and perhaps even more difficult are the evaluation of the meaning of transpiration and plant temperature not only for photosynthesis, but also for the way in which photosynthates are utilized by the plant in, for example, leaf initiation and leaf expansion. In the classical methods of growth analysis, the importance of photosynthesis for plant performance tended to be underestimated, that of growth phenomena to be overestimated. At present there is a tendency for the reverse to be true.

3) Climate rooms can be a useful tool for getting information about the relation between photosynthetic rate and utilization of photosynthates by the plant. Prerequisite is that through manipulation of the environment, processes directly affected can be varied as independently as possible over ranges to be expected in nature. The processes are photosynthesis, transpiration rate, and all temperature-dependent processes (through effects of the environment upon plant temperature). For this purpose, high irradiances in the photosynthetically active part of the spectrum are required. Independent variation of photosynthesis, trar. spiration, and plant temperature then becomes a problem, in particular because the wind speeds applied usually are very low, between for example 10 to $40 \mathrm{~cm} \mathrm{sec}^{-1}$, resulting in high boundary layer resistances. Our experiments with model leaves have shown that the boundary layer resistance then is in the order of $0.5-1.5 \mathrm{sec} \mathrm{cm}^{-1}$, whereas for an acceptable coupling between for example leaf temperature and transpiration rate, its size should be $0.25 \mathrm{sec} \mathrm{cm}^{-1}$ or less, see Table 6D-1.

The problem of getting low $r_{a}$-values is closely related with the effect of various factors upon the drag force at a leaf surface, as presented in Fig. 6-4 of Lemon's paper. The situation for a model leaf could differ from that of a real leaf through effects of surface roughness, flexibility, and local convections at the leaf surface. It would be extremely important if micrometeorologists could provide the users of growth rooms with an evaluation of the effects of these factors as compared with those of wind speed, leaf area, and leaf shape. If wind speed would be the dominant factor, this speed should be increased for those experiments in which transpiration rate and leaf temperature should be uncoupled as much as possible.

If windspeeds have to be increased up to 1 or $2 \mathrm{~m} \mathrm{sec}{ }^{-1}$, this cer tainly gives technical problems which can be solved, but it is unlikely that this also would be unfavorable for plant growth, as sometimes is stated. Table 6D-1 shows that lowering of $r_{a}$ can result in considerably 
Table 6D-1-Transpiration rate and difference between leaf and air temperature $\left(t_{1}-t_{a}\right)$ as affected by boundary layer resistance $\left(r_{a}\right)$ and vapor pressure deficit of the air. Leaf resistance $r_{1}=1 \mathrm{sec} \mathrm{cm}{ }^{-1}$; absorbed radiation $=0.3 \mathrm{cal} \mathrm{cm}^{-2}$ $\min ^{-1} ; \mathrm{t}_{\mathrm{a}}=20 \mathrm{C}$.

\begin{tabular}{clccccc}
\hline & & \multicolumn{4}{c}{ Vapor deficit air, $\mathrm{mm} \mathrm{Hg}$} \\
\cline { 3 - 7 } & $\mathrm{r}_{\mathrm{a}}\left(\mathrm{sec} \mathrm{cm}^{-1}\right)$ & 0 & 2.5 & 5 & 7.5 & 10 \\
\hline Transpiration rate & 2.0 & 0.80 & 1.01 & 1.22 & 1.43 & 1.64 \\
$\left(\mathrm{~g} \mathrm{dm}^{-2} \mathrm{~h}^{-1}\right)$ & 1.0 & 0.80 & 1.12 & 1.44 & 1.76 & 2.08 \\
& 0.25 & 0.48 & 1.16 & 1.65 & 2.23 & 2.82 \\
$\mathrm{t}_{1}-\mathrm{t}_{\mathrm{a}}\left({ }^{\circ} \mathrm{C}\right)$ & 2.0 & 6.47 & 5.85 & 5.22 & 4.60 & 3.97 \\
& 1.0 & 4.28 & 3.66 & 3.04 & 2.42 & 1.80 \\
& 0.25 & 1.62 & 1.25 & 0.87 & 0.50 & 0.12 \\
\hline
\end{tabular}

increased transpiration rate at large vapor pressure deficits. However, good control of air humidity would prevent excessive transpiration rates to occur. These relations are demonstrated in Table 6D-1.

Higher wind speeds also induce movements of plant parts. It seems unlikely that the moderate movements to be expected at windspeeds between 1 and $2 \mathrm{~m} \mathrm{sec}^{-1}$ would have an unfavorable mechanical effect upon plant performance. Nevertheless, it would be worthwhile to investigate the nature of such effects more closely.

4) Micrometeorological methods of measuring gaseous exchange are not likely to become a tool for routine measurements. A team of highly skilled personnel and sophisticated equipment is needed to make measurements and for the handling and interpretation of measured items. Large assimilation chambers used outside during short periods in the order of minutes, could give useful information about instantaneous photosynthetic rates of crop canopies. The proper use of such chambers depends upon the insight we get into the effects of air movement upon boundary layer resistance and, consequently, upon photosynthesis. It might well be that changes of transpiration rate and leaf temperature in many cases do not have a large influence upon photosynthesis in short-time experiments. 